\title{
Sex differences in the association between diabetes and risk of cardiovascular disease, cancer, and all-cause and cause-specific mortality: a systematic review and meta- analysis of 5,162,654 participants
}

Yafeng Wang ${ }^{1}$, Adrienne $\mathrm{O}^{\prime}$ Neil $^{2}$, Yurui Jiao ${ }^{3}$, Lijun Wang ${ }^{4}$, Jingxin Huang ${ }^{5}$, Yutao Lan ${ }^{5}$, Yikun Zhu ${ }^{3 *}$ and Chuanhua $\mathrm{Yu}^{1,6^{*}}$

\begin{abstract}
Background: Studies have suggested sex differences in the mortality rate associated with diabetes. We conducted a meta-analysis to estimate the relative effect of diabetes on the risk of all-cause, cancer, cardiovascular disease (CVD), infectious disease, and respiratory disease mortality in women compared with men.

Methods: Studies published from their inception to April 1, 2018, identified through a systematic search of PubMed and EMBASE and review of references. We used the sex-specific RRs to derive the women-to-men ratio of RRs (RRR) and $95 \% \mathrm{Cls}$ from each study. Subsequently, the RRR for each outcome was pooled with random-effects metaanalysis weighted by the inverse of the variances of the log RRRs.

Results: Forty-nine studies with 86 prospective cohorts met the inclusion criteria and were eligible for analysis. The pooled women-to-men RRR showed a 13\% greater risk of all-cause mortality associated with diabetes in women than in men (RRR $1.13,95 \% \mathrm{Cl} 1.07$ to $1.19 ; P<0.001$ ). The pooled multiple-adjusted RRR indicated a 30\% significantly greater excess risk of CVD mortality in women with diabetes compared with men (RRR $1.30,95 \% \mathrm{Cl}$ 1.13 to $1.49 ; P<0.001)$. Compared with men with diabetes, women with diabetes had a $58 \%$ greater risk of coronary heart disease (CHD) mortality, but only an $8 \%$ greater risk of stroke mortality (RRR $\mathrm{CHD}_{\mathrm{CH}} 1.58,95 \% \mathrm{Cl} 1.32$ to 1.90; $P<0.001 ; R_{R R}$ stroke $1.08,95 \% \mathrm{Cl} 1.01$ to $\left.1.15 ; P<0.001\right)$. However, no sex differences were observed in pooled results of populations with or without diabetes for all-cancer (RRR 1.02, 95\% Cl 0.98 to $1.06 ; P=0.21$ ), infectious (RRR $1.13,95 \% \mathrm{Cl} 0.90$ to $1.38 ; P=0.33$ ), and respiratory mortality (RRR $1.08,95 \% \mathrm{Cl} 0.95$ to $1.23 ; P=0.26$ ).
\end{abstract}

Conclusions: Compared with men with the same condition, women with diabetes have a 58\% and 13\% greater risk of CHD and all-cause mortality, respectively, although there was a significant heterogeneity between studies. This points to an urgent need to develop sex- and gender-specific risk assessment strategies and therapeutic interventions that target diabetes management in the context of CHD prevention.

Keywords: Diabetes, Sex difference, Mortality, Meta-analysis

\footnotetext{
*Correspondence: yuchua@whu.edu.cn; zyk1003@sxmu.edu.cn

1 Department of Epidemiology and Biostatistics, School of Health Sciences,

Wuhan University, 185 Donghu Road, Wuchang District, Wuhan 430071,

China

${ }^{3}$ Department of Endocrinology, Second Clinical Medical College, Shanxi

Medical University, 382 Wuyi Road, Taiyuan 030001, China

Full list of author information is available at the end of the article
}

(c) The Author(s). 2019 Open Access This article is distributed under the terms of the Creative Commons Attribution 4.0 International License (http://creativecommons.org/licenses/by/4.0/), which permits unrestricted use, distribution, and reproduction in any medium, provided you give appropriate credit to the original author(s) and the source, provide a link to the Creative Commons license, and indicate if changes were made. The Creative Commons Public Domain Dedication waiver (http://creativecommons.org/publicdomain/zero/1.0/) applies to the data made available in this article, unless otherwise stated. 


\section{Background}

According to the Global Burden of Disease Study (GBD), non-communicable diseases (NCDs) are the main cause of premature deaths amongst the world's population [1]. As one of four main NCDs, diabetes affected an estimated 387 million people throughout the world and caused around 1.3 million deaths worldwide in 2010 alone [2-4]. With the increasing prevalence of physical inactivity and obesity, the burden of diabetes is predicted to increase to 592 million by 2035 , making it a major contributor to the global burden of disease [5].

Type 2 diabetes mellitus is associated with an approximate twofold increase in the risk of all-cause mortality as well as death from cardiovascular disease (CVD), kidney disease, infectious disease, respiratory disease, and several specific forms of cancer [6]. Previous metaanalyses, through internal, within-study comparisons of female and male participants, have observed that women with diabetes are at substantially higher risk of coronary heart disease (CHD), stroke, and gastric cancer compared to affected men. On the other hand, no sex differences were found between diabetes and the risk of esophageal cancer, colorectal cancer, and pancreatic cancer [7-9]. However, the magnitude of the excess risk of these and other cause-specific outcomes that are conferred by diabetes for men and women is unknown. Furthermore, it is unclear whether important confounders (e.g., age) and methodological heterogeneity (duration of follow-up, method of diabetes classification or assessment) would modify any such sex differential in the association between diabetes and mortality. It is also unclear whether such a difference might be more pronounced in recent years with the growing obesity epidemic (e.g., year of publication).

Accordingly, we sought to conduct a meta-analysis of prospective cohort studies in order to (i) calculate any sex differential in the association between diabetes and risk of cardiovascular disease, cancer, and all-cause and cause-specific mortality for the general population and (ii) to determine whether these associations are modified by demographics, setting, length of follow-up, diabetes measurement, and recency of publication.

\section{Methods}

\section{Search strategy}

The meta-analysis was performed in accordance with the Meta-Analysis of Observational Studies in Epidemiology guidelines [10] and the Preferred Reporting Items for Systematic Reviews and Meta-Analyses statement [11] (Additional file 1: Table S1). We searched the PubMed and EMBASE databases from their inception to April 1, 2018. Details of the search strategy using a combined text word and medical subject heading are displayed in Additional file 1. The articles were restricted to English language studies. Moreover, the reference lists of the retrieved publications and reviews were checked for other potentially relevant studies.

\section{Study selection}

Studies were included if they met the following criteria: (1) the study was a prospective cohort design; (2) the outcomes included all-cause mortality, cancer mortality, CVD mortality, CHD mortality, stroke mortality, infectious disease mortality, and/or respiratory disease mortality; (3) the studies provided odds ratio (OR), relative risk (RR), or hazard ratio (HR) with $95 \%$ confidence intervals $(\mathrm{CI})$ for the associations between diabetes and mortality disaggregated for men and women participants; and (4) when multiple publications reported on the same population or subpopulation, the study with the most recent or most informative data was included. The exclusion criteria were as follows: (1) matched prospective cohort study design, (2) studies reporting only estimates for type 1 diabetes, (3) studies not adjusting for age, and (4) studies of populations that predominantly consisted of individuals with underlying pathological disorders, such as cardiovascular disease or cancer. We also used individual participant data from the America's National Health Interview Surveys (1997 to 2009) linked to the National Death Index records through December 31, 2011. Extensive details about the questionnaire, methodology, data, and documentation are available on the NHIS website. [https://www.cdc. gov/nchs/nhis/about_nhis.htm].

\section{Data extraction and study quality assessment}

Two investigators (YFW and YRJ) independently reviewed all potentially eligible studies using predefined criteria and extracted the data from each paper. In case of incomplete or unclear data, the authors were contacted where possible. The cohort study quality was estimated using the nine-star Newcastle-Ottawa quality assessment Scale (NOS) ranging from zero to nine stars [12]. Disagreements were resolved by consensus between the authors.

\section{Statistical analysis}

The RR was used as a measure of the association between diabetes and outcome risk. For individual participant data, we used Cox proportional hazards regression to obtain HRs (regarded as RRs). If the included studies did not report the RRs, the HRs were directly considered as RRs and the ORs were converted into RRs using the formula: $\mathrm{RR}=\mathrm{OR} /[(1-\mathrm{Po})+(\mathrm{OR} \times \mathrm{Po})]$, in which $\mathrm{Po}$ was the incidence of the outcome of interest in the nondiabetes group [13]. For studies that reported RRs in different age groups, we pooled these RRs with inverse variance random-effect models, and then we used 
combined estimates for that study. For the primary analysis, we used the sex-specific RRs to derive the womento-men ratio of RRs (RRR) and 95\% CIs from each study, as previously described [14]. Subsequently, the RRR for each outcome was pooled with random-effects metaanalysis weighted by the inverse of the variances of the $\log$ RRRs. We also pooled RRs for men and women separately, using an identical approach. The heterogeneity among the included studies was evaluated by the $Q$ test and $I^{2}$ statistic [15].

Subsequently, where the number of included studies was more than 10 for each outcome of interest, sensitivity analyses were performed by mean age $(\leq 60$ versus $>$ 60 years), region (Asia versus Europe versus America versus others), publish year ( $\leq 2000$ versus $2001-2009$ versus $\geq 2010)$, length of follow-up ( $\leq 10$ versus $>10$ years), and ascertainment of diabetes (known diabetes versus newly diagnosed diabetes versus both). Random- effects meta-regression analyses were used to evaluate whether the differences in the mean/medium duration of study follow-up and mean age of participants at baseline contributed to the heterogeneity between the studies. Publication bias was assessed by Begg's rank correlation test and its funnel plots of the natural log of the RRR against its standard error [16]. Where publication bias was detected, trim and fill analyses were used to adjust the RRs or ratio of RRs. All statistical analyses were performed with Stata version 13.0 (StataCorp, College Station, TX, USA).

\section{Results}

Of the 24,303 references identified through the systematic search, 375 were examined in the full-text review (Fig. 1). In addition, 6 articles were retrieved from the reference lists of relevant articles and reviews. Subsequently, individual participant data from NHIS were

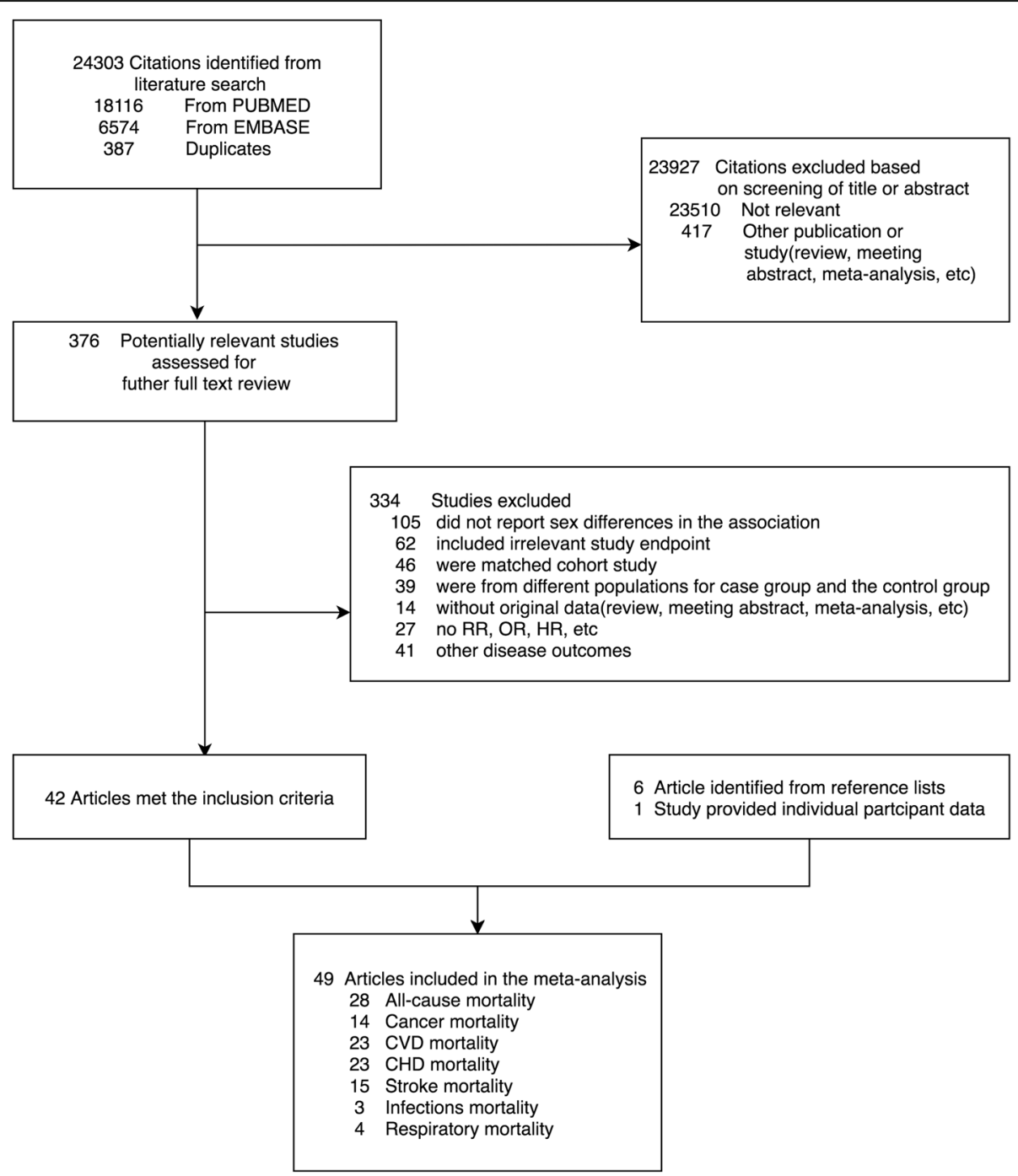

Fig. 1 Flowchart for study selection for the meta-analysis 
added to these published results. Finally, 49 studies with 86 prospective cohorts met the inclusion criteria and [17-63] were eligible for analysis (Table 1).

The characteristics of the included studies are described in Table 1. Baseline surveys were conducted between 1950 and 2014, and the number of participants ranged from 379 to $1,298,358$. The mean/median duration of follow-up ranged from 6.0 to 21.4 years, while the average baseline age was between 33.3 and 80.0 years. The quality of all included studies based on NOS was high (Additional file 1: Table S2). All studies adjusted for age and most of the studies also controlled for smoking $(n=77)$, hypertension $(n=71)$, and body mass index $(n=68)$.

Twenty-eight studies with $3,887,585$ participants were included to assess the sex-specific association between diabetes and all-cause mortality. For cause-specific mortality, 14 studies with 4,482,501 reported on cancer mortality, 23 studies with 2,067,486 reported on CVD mortality, 23 studies with 2,050,929 reported on CHD mortality, 15 studies with 2,292,387 reported on stroke mortality, 4 studies with 1,633,520 reported on respiratory disease mortality, and 3 studies with 1,638,651 reported on infectious disease mortality.

\section{Sex-specific association between diabetes and risk of all- cause, cancer, CVD, infectious disease, and respiratory disease mortality}

The pooled multiple-adjusted RRs of all-cause mortality associated with diabetes compared with no diabetes were 1.93 (95\% CI 1.80 to 2.06; Fig. 2) in women and 1.74 (1.67 to 1.82 ) in men. The pooled women-to-men RRR showed a $13 \%$ greater risk of all-cause mortality associated with diabetes in women than in men (RRR 1.13, 95\% CI 1.07 to $1.19 ; P<0.001$; Figs. 3 and 4 ). There was, however, a significant heterogeneity between the studies $\left(I^{2}=60 \%, P<0.001\right.$; Fig. 2).

The pooled multiple-adjusted RRs showed that diabetes was associated with a $26 \%$ (1.16 to 1.36$)$ increased risk for cancer mortality in women and a $29 \%$ (1.18 to 1.42; Additional file 1: Figure S1) increased risk in men. There was no evidence of a sex difference in the association between diabetes and cancer mortality; the pooled multiple-adjusted RRR of cancer mortality for diabetes was 1.02 (0.98 to $1.06 ; P=0.21$; Fig. 4 ; Additional file 1 : Figure S2). No evidence of significant between-study heterogeneity was found $\left(I^{2}=0 \% ; P=0.60\right)$.

Compared with unaffected individuals, the pooled RR for CVD mortality in people with diabetes was 2.42 (2.10 to 2.78; Additional file 1: Figure S3) in women and 1.86 (1.70 to 2.03) in men. Overall, the pooled multipleadjusted RRR indicated a 30\% significantly greater excess risk of CVD mortality in women with diabetes compared with men (RRR 1.30, 95\% CI 1.13 to $1.49 ; P<0.001$;
Fig. 4; Additional file 1: Figure S4), but with significant heterogeneity between the studies $\left(I^{2}=78 \%, P<0.001\right)$. In addition, the pooled RR of CHD mortality for individuals with diabetes compared with those without diabetes was higher in women than in men [women, 3.16 (2.61 to 3.82); men, 2.11 (1.98 to 2.25); both $P<0.001$; Additional file 1: Figure S5]. Compared with men with diabetes, women with diabetes had a $58 \%$ greater risk of CHD mortality, but only an $8 \%$ greater risk of stroke mortality [CHD mortality (RRR 1.58, 95\% CI 1.32 to 1.90; $P<0.001$; Additional file 1: Figure S6); stroke mortality (RRR 1.08, 95\% CI 1.01 to 1.15 ; $P<0.001$; Additional file 1: Figure S7); Fig. 4]. Moreover, there was no heterogeneity between the studies examining stroke mortality, but significant heterogeneity between the studies for CHD mortality [CHD mortality $\left(I^{2}=67 \%\right.$, $P<0.001)$; stroke mortality $\left.\left(I^{2}=0 \%, P=0.74\right)\right]$.

Compared with those without, women and men with diabetes had approximately $31 \%$ and $22 \%$ greater risk of respiratory disease mortality, respectively (Additional file 1 : Figure S8). However, no sex differences were observed (RRR 1.08, 95\% CI 0.95 to $1.23 ; P=0.26$; Fig. 4) nor significant heterogeneity $\left(I^{2}=0 ; P=0.98\right)$.

Diabetes was associated with an approximately twofold increase in the risk of infectious disease-related mortality [women, 2.13 (1.89 to 2.42); men, 1.94 (1.66 to 2.26); both $P<0.001$; (Additional file 1: Figure S9)]. There was no evidence of sex differences (RRR 1.11, 95\% CI 0.90 to 1.38; $P=0.33$; Fig. 4).

Subgroup, meta-regression, and publication bias analyses We performed subgroup analyses for cancer, CHD, stroke, CVD and all-cause mortality outcomes. Results showed no evidence of heterogeneity between the subgroups stratified by study characteristics including age, geographical location, duration of follow-up, publish year, and method of diabetes ascertainment (Table 2). For the method of diabetes ascertainment, sex differences for CVD, CHD, and all-cause mortality conferred by diabetes were only significant in self-reported diagnosis (all-cause mortality: RRR $1.17,95 \%$ CI 1.07 to $1.27, P<0.001$; CVD mortality: RRR 1.20, 95\% CI 1.02 to $1.42, P<0.001$; CHD mortality: RRR $1.52,95 \%$ CI 1.20 to $1.92, P<0.001)$. The pooled RRR for CHD, stroke, CVD, and all-cause mortality did not vary by mean age of the participants at baseline, mean/medium duration of follow-up, baseline prevalence of diabetes, and women-to-men ratio of diabetes prevalence (all $P>0.1$ ). We found no evidence of publication bias for cancer, $\mathrm{CHD}$, stroke, CVD, respiratory disease, infectious disease, and allcause mortality $(P>0.10)$.

\section{Discussion}

This systematic review and meta-analysis of 49 studies with 86 prospective cohorts found that diabetes conferred 


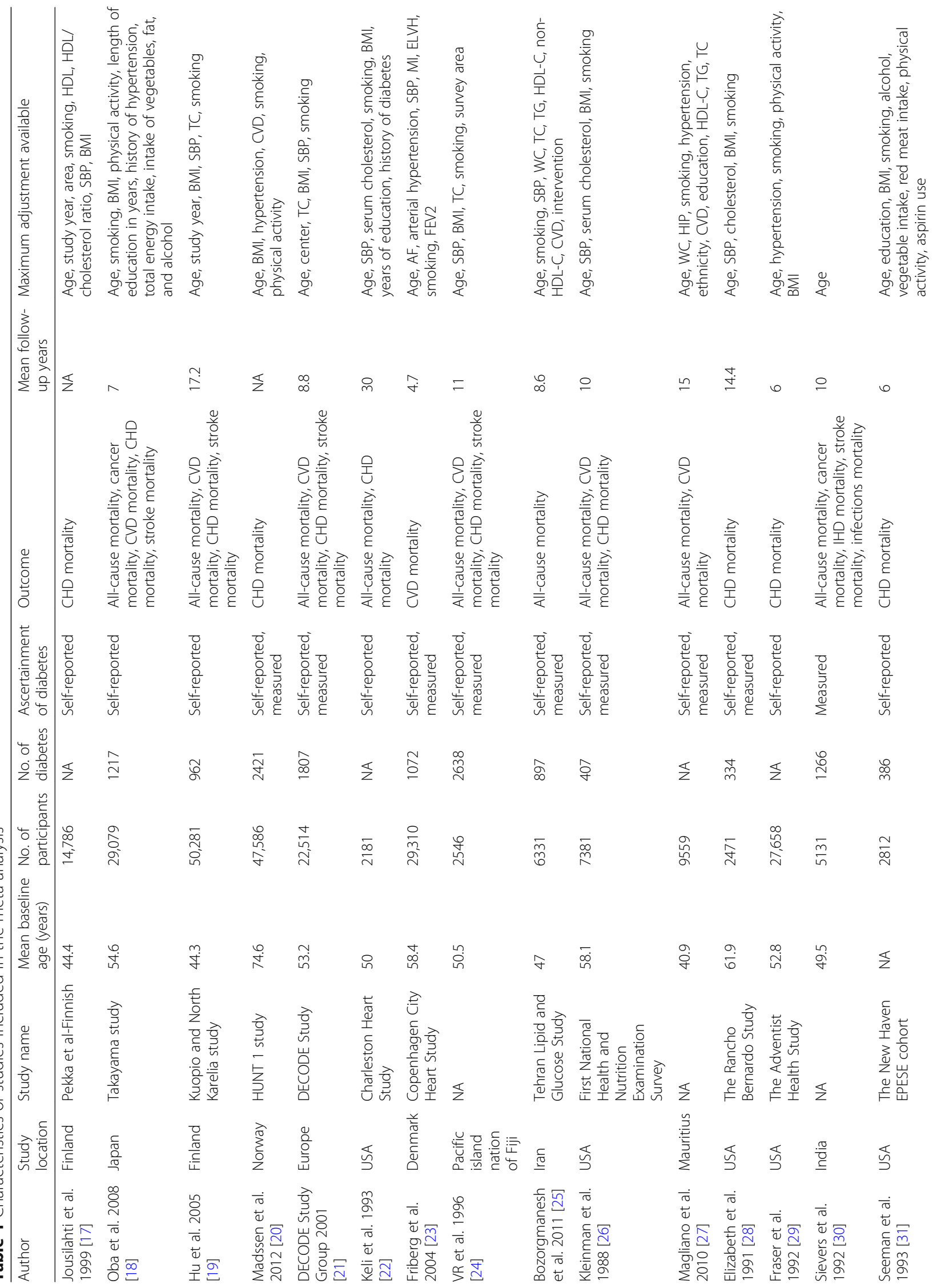




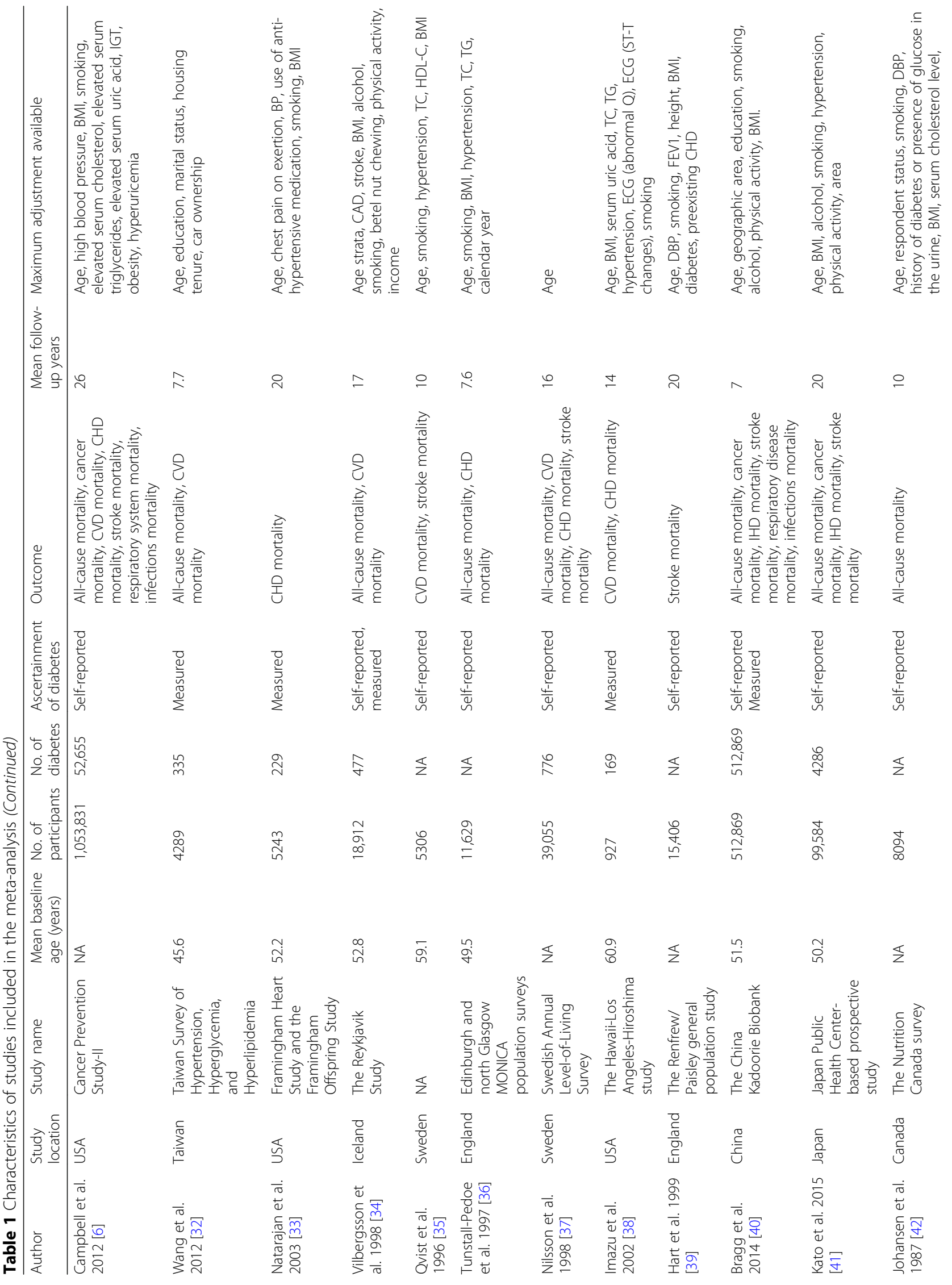




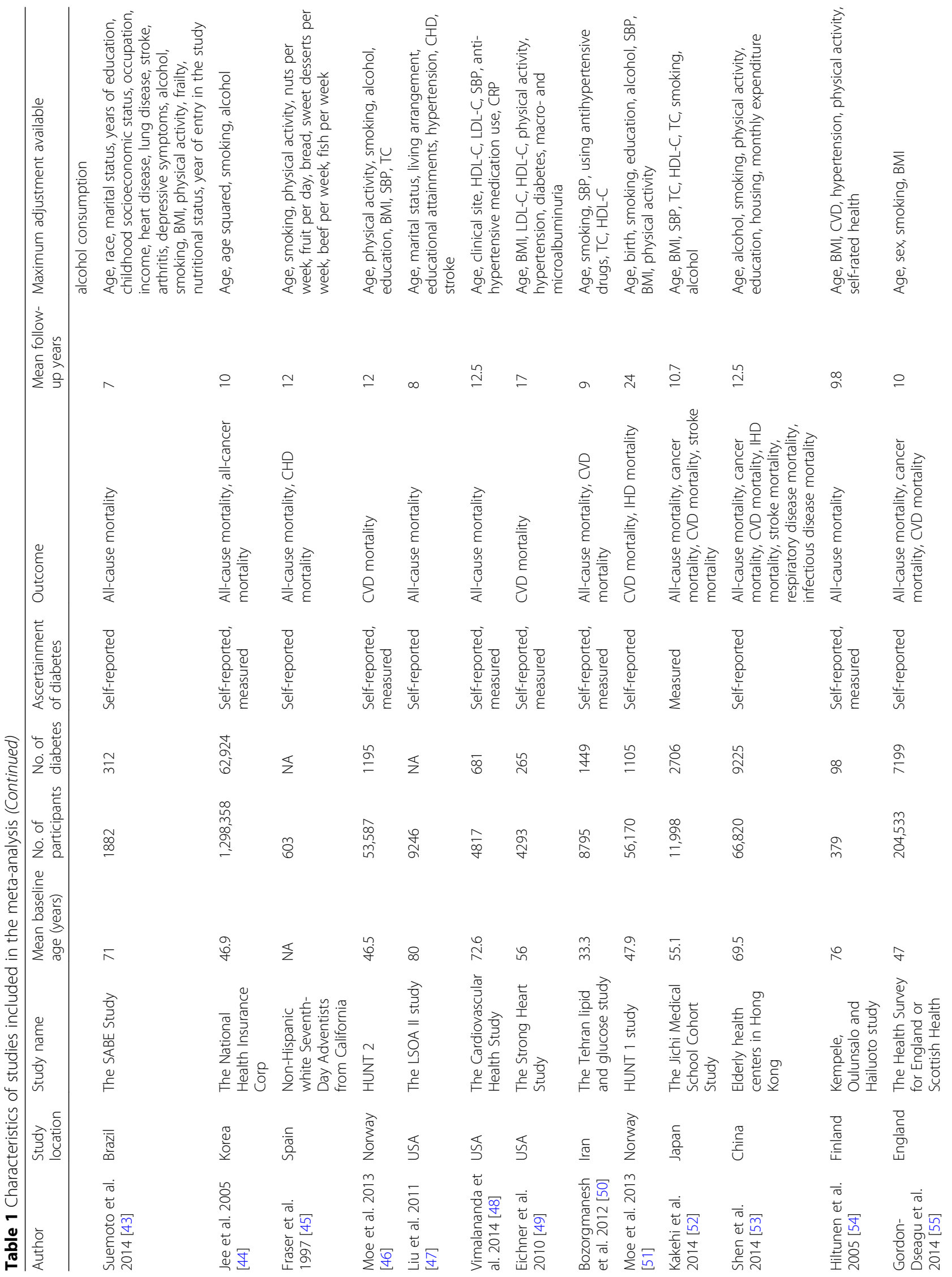




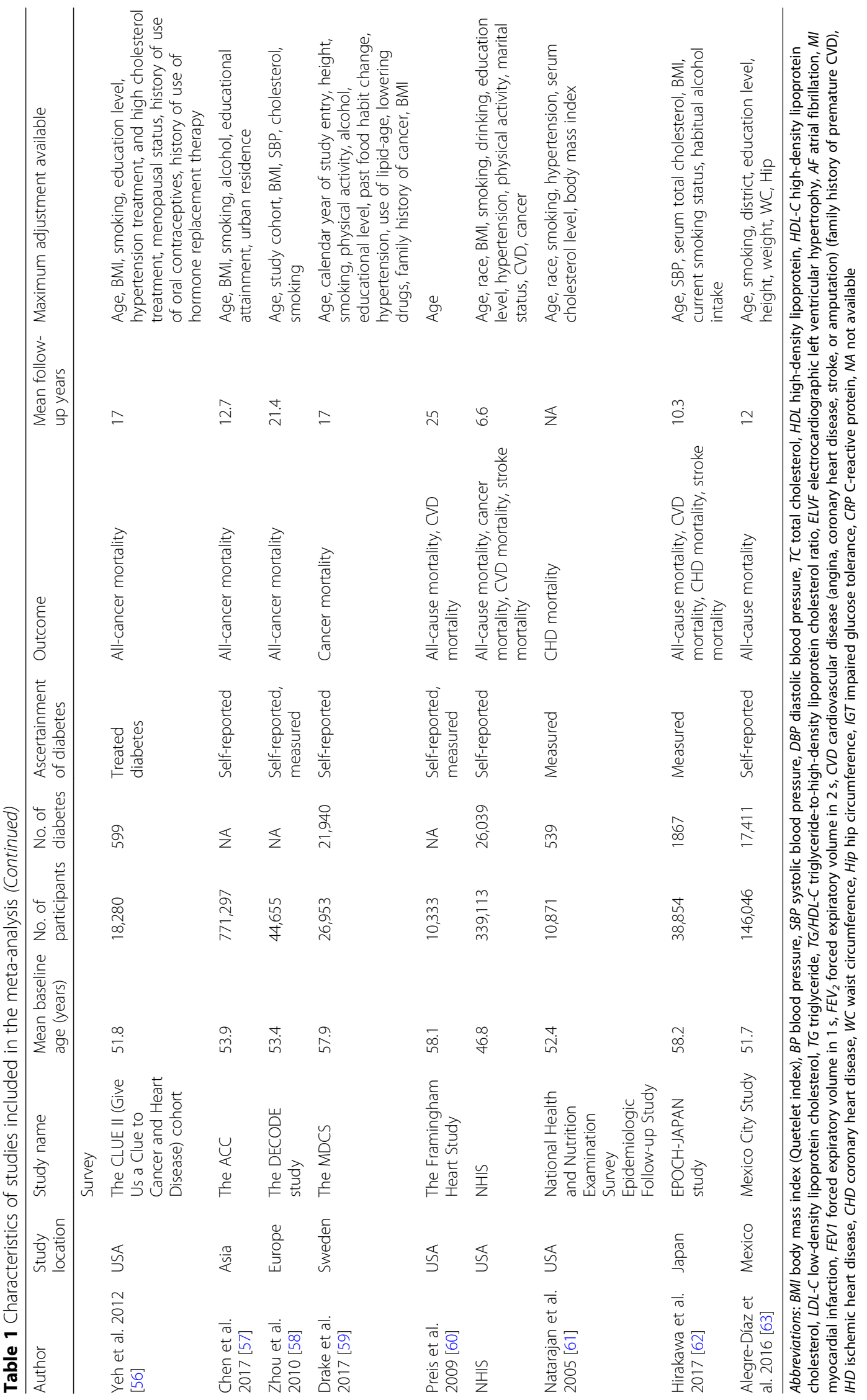




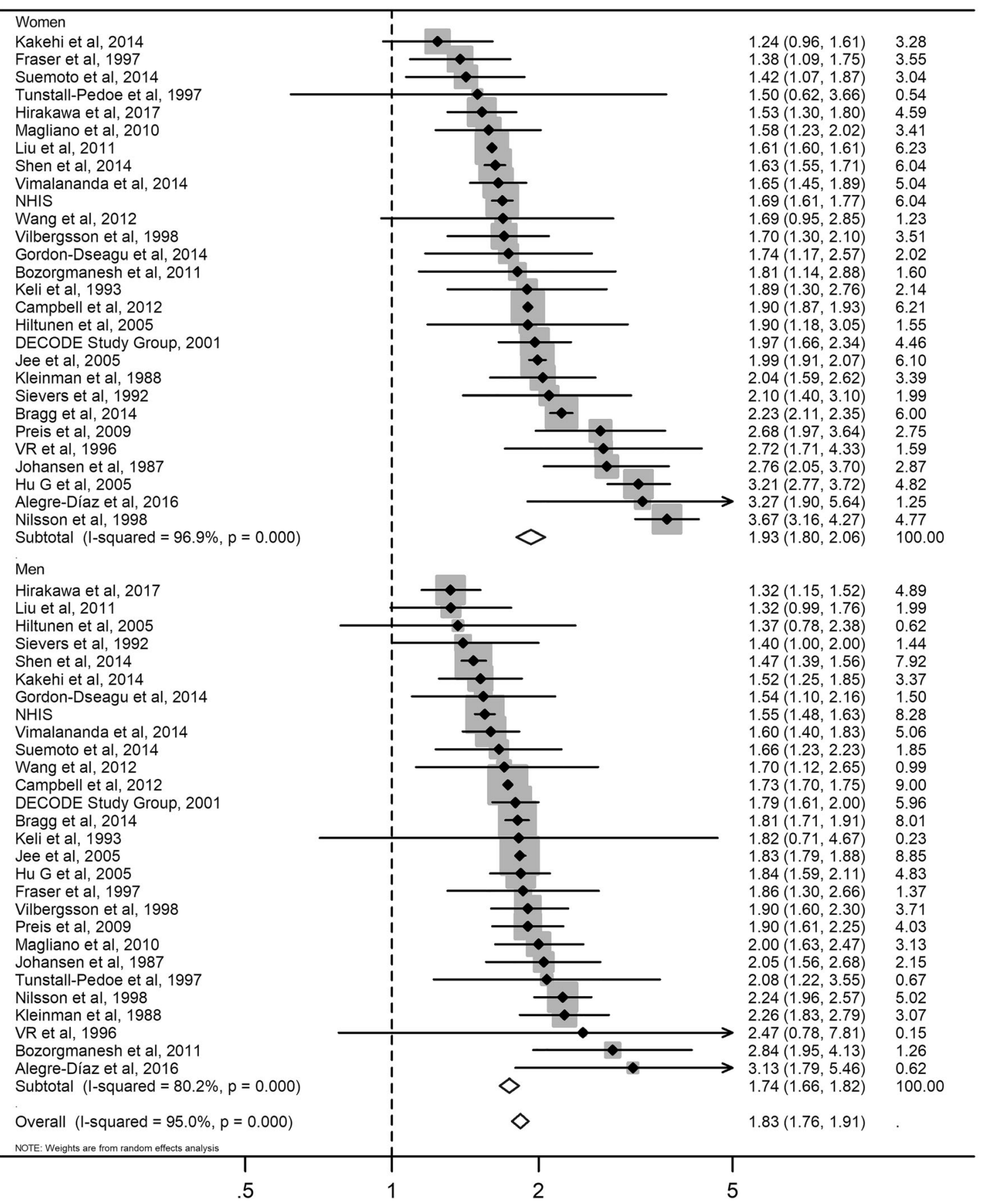

Lower RR in diabetes

Higher RR in diabetes

Fig. 2 Pooled RRs for risk of all-cause mortality 
Bozorgmanesh et al, 2011

Tunstall-Pedoe et al, 1997

Fraser et al, 1997

Magliano et al, 2010

Kakehi et al, 2014

Suemoto et al, 2014

Vilbergsson et al, 1998

Kleinman et al, 1988

Wang et al, 2012

Vimalananda et al, 2014

Keli et al, 1993

Alegre-Díaz et al, 2016

$\mathrm{NHIS}$

Jee et al, 2005

DECODE Study Group, 2001

Campbell et al, 2012

VR et al, 1996

Shen et al, 2014

Gordon-Dseagu et al, 2014

Hirakawa et al, 2017

Liu et al, 2011

Bragg et al, 2014

Johansen et al, 1987

Hiltunen et al, 2005

Preis et al, 2009

Sievers et al, 1992

Nilsson et al, 1998

Hu G et al, 2005

Overall (I-squared $=60.1 \%, p=0.000)$

NOTE: Weights are from random effects analysis

$$
1
$$

Higher RRR in men

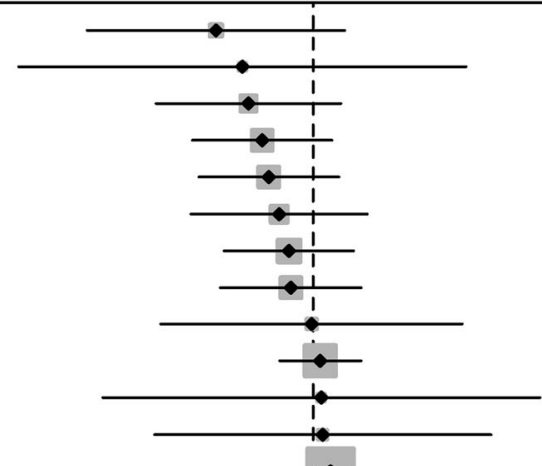

$0.64(0.35,1.16) \quad 0.73$

$0.72(0.26,2.03) \quad 0.25$

$0.74(0.48,1.14) \quad 1.33$

$0.79(0.57,1.09) \quad 2.17$

$0.82(0.59,1.13) \quad 2.17$

$0.86(0.57,1.29) \quad 1.46$

$0.89(0.66,1.21) \quad 2.45$

$0.90(0.65,1.25) \quad 2.14$

$0.99(0.49,2.00) \quad 0.54$

$1.04(0.86,1.25) \quad 4.83$

$1.04(0.38,2.86) \quad 0.26$

$1.05(0.48,2.28) \quad 0.44$

$1.09(1.02,1.16) \quad 10.67$

$1.09(1.04,1.14) 11.73$

$1.10(0.90,1.35) \quad 4.38$

$1.10(1.07,1.12) \quad 12.69$

$1.10(0.32,3.82) \quad 0.17$

$1.11(1.03,1.20) \quad 10.19$

$1.13(0.67,1.89) \quad 0.94$

$1.16(0.94,1.44) \quad 4.08$

$1.21(0.91,1.62) 2.68$

$1.23(1.14,1.33) \quad 10.11$

$1.35(0.90,2.01) 1.51$

$1.39(0.67,2.89) \quad 0.49$

$1.41(0.99,2.00) 1.91$

$1.50(0.89,2.54) \quad 0.91$

$1.64(1.34,2.01) \quad 4.41$

$1.74(1.42,2.14) \quad 4.35$

$1.13(1.07,1.19) \quad 100.00$

1

3

Higher RRR in women

Fig. 3 Pooled women-to-men RRRs for risk of all-cause mortality

a greater risk for almost all outcomes of interest. Diabetes appears to be a stronger risk factor for CHD, CVD, and all-cause mortality in women than in men. Of note, compared to men with diabetes, women with the same condition had 57\% excess risk for CHD. Although diabetes was associated with a higher risk of cancer mortality, infectious disease, and respiratory disease mortality, we did not observe a sex difference between diabetes and mortality. Interestingly, however, these results were only upheld in studies that used self-reporting measures to identify diabetes cases.

Diabetologists and epidemiologists have long been aware that diabetes has pronounced cardiovascular consequences for women, irrespective of diabetes type $[10,28,64]$. Indeed, CVD is the leading cause of morbidity and mortality for individuals with diabetes, which accounts for $>50 \%$ of all deaths [65]. We found that for women, diabetes confers a 54\% excess risk of CHD death. While such sex-specific differences are of increasing interest in cardiology and medical fields, the underpinning mechanisms driving this association are not entirely clear. The pathogenesis seems to be multifactorial with contributions from sex differences in genetic and biological factors, gender disparities from cultural and environmental factors, and the well-documented differences in the diagnosis, management, and treatment of DM and CVD of women and men [66-68].

The putative biological mechanisms have centered on the effects of estrogen which can deplete during menopause to elevate women's CHD risk [69]. Testosterone 


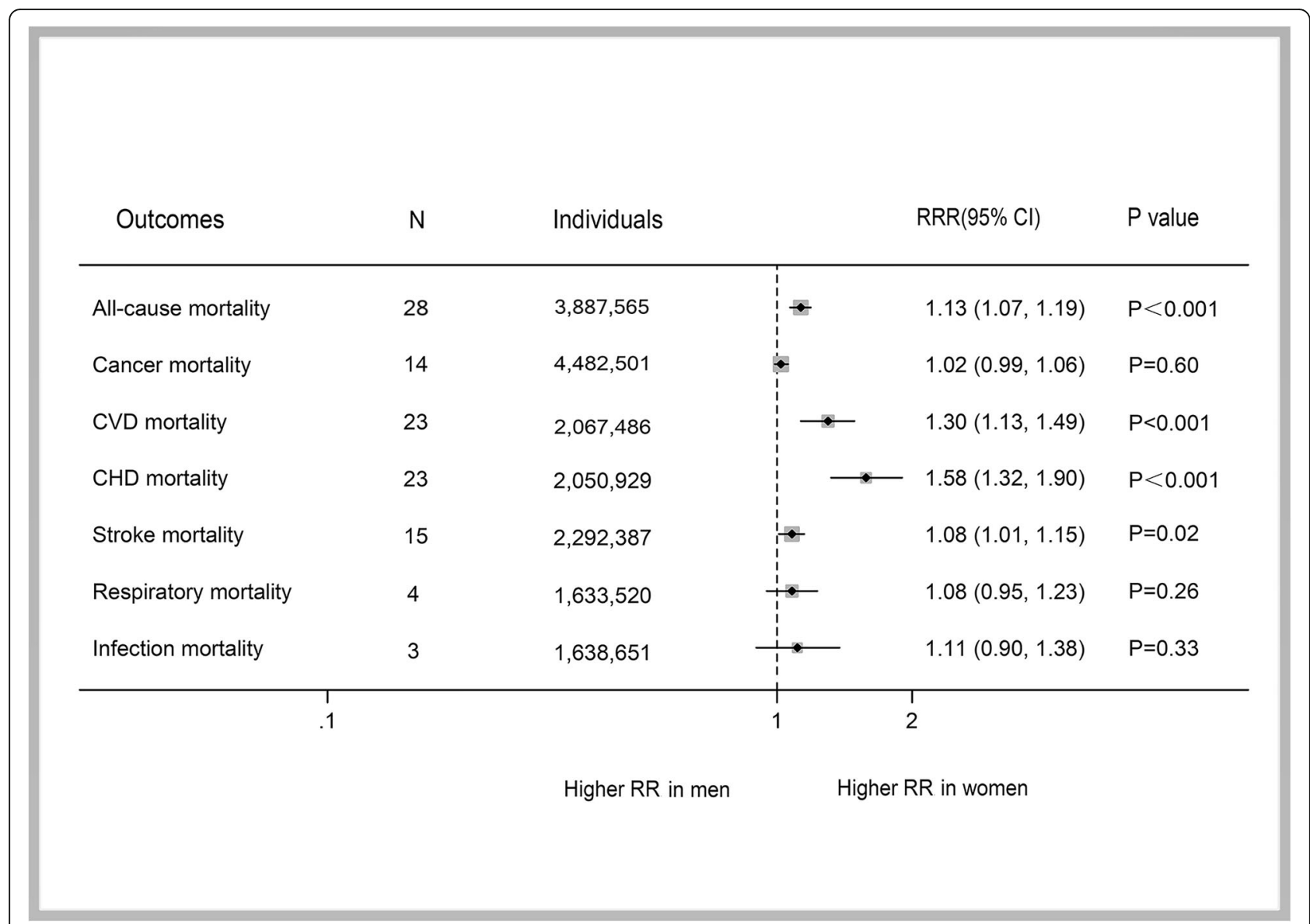

Fig. 4 Pooled women-to-men RRRs for risk of all-cause, cancer, CVD, CHD, stroke, respiratory, and infectious mortality

may be involved in different mechanisms attributed to sex differential in CHD risk [70-72]. In men, higher total testosterone levels are associated with reduced risk of future CHD and ischemic stroke. Testosterone has anabolic effects, promoting muscle mass and strength [73]. The recent prospective cohort study of half a million UK Biobank participants showed that higher grip strength was associated with a lower risk of incidence of and mortality from CVD [74]. Compared with men, women with lower testosterone levels have low mass and strength of muscle, which also partially explain greater risk for $\mathrm{CHD}$ death conferred by diabetes in women compared with men.

Women with diabetes are more likely to have poor risk factor profiles and suffer greater disease risk owing to the effects of individual risk factors. A recent metaanalysis showed that smoking conferred $25 \%$ excess risk for CHD in women than in men [7]. In addition, women with diabetes remain less likely to achieve high-density lipoprotein cholesterol targets and have a higher prevalence of obesity than men [75-77]. Whether existing sex differences in diabetic heart disease are magnified by sex differences in traditional and modifiable cardiac risk factors requires consideration. Recently, a meta-analysis of individual data from 68 prospective studies showed that body mass index, blood pressure, and total cholesterol each had continuous log-linear associations with CHD or stroke mortality that were similar in strength among those with and those without diabetes, irrespective of sex [78]. Our other study found that compared with men with metabolic syndrome, women with metabolic syndrome had a significant $16 \%$ higher risk of CHD incidence (RRR 1.16, 95\% CI 1.01 to $1.34 ; P=0.04$ ), and the significant sex difference disappeared in non-diabetes population (RRR $0.92,95 \%$ CI 0.73 to $1.17 ; P=0.50$ ). This partly supported the hypothesis that the stronger detrimental effects of diabetes for women than for men in CVD could not be explained by the different levels of established major CVD risk factors and their clusters. Differences in the clinical manifestation of diabetes warrants further consideration. Prediabetes is associated with an increased risk of cardiovascular disease [79], and the sex differences in the nonphysiological effects can be partly accounted for the diabetes-related excess risk of CVD in women. In the prediabetic state, impaired glucose tolerance may be more serious in women than in men $[80,81]$. 
Table 2 Sensitivity analyses of women-to-men ratio of relative risks for the outcomes associated with diabetes

\begin{tabular}{|c|c|c|c|c|c|c|c|c|c|c|}
\hline & \multirow[t]{2}{*}{ Individuals } & \multirow[t]{2}{*}{$N$} & \multirow[t]{2}{*}{ RRR } & \multirow[t]{2}{*}{ Lower } & \multirow[t]{2}{*}{ Upper } & \multirow[t]{2}{*}{$P$ value } & \multicolumn{3}{|c|}{ Test for heterogeneity } & \multirow[t]{2}{*}{$P$ value for interaction } \\
\hline & & & & & & & $\bar{R}(\%)$ & $x^{2}$ & $P$ value & \\
\hline All-cause mortality & $3,887,585$ & 28 & & & & & & & & \\
\hline Age (years) & & & & & & & & & & 0.97 \\
\hline$<60$ & $2,517,958$ & 17 & 1.10 & 1.01 & 1.21 & 0.03 & 64.60 & 45.24 & $<0.001$ & \\
\hline$\geq 60$ & 268,044 & 7 & 1.10 & 1.04 & 1.18 & $<0.001$ & 0.00 & 3.00 & 0.81 & \\
\hline Others & $1,101,583$ & 4 & 1.19 & 0.91 & 1.57 & 0.21 & 84.30 & 19.05 & $<0.001$ & \\
\hline Location & & & & & & & & & & 0.63 \\
\hline Asia & 1944.650 & 8 & 1.12 & 1.03 & 1.21 & 0.05 & 56.00 & 15.89 & 0.03 & \\
\hline Western Europe & 347,906 & 8 & 1.18 & 0.93 & 1.50 & 0.18 & 76.40 & 29.69 & $<0.001$ & \\
\hline North America & $1,572,948$ & 8 & 1.10 & 1.08 & 1.12 & $<0.001$ & 0.00 & 4.33 & 0.74 & \\
\hline Others & 22,081 & 4 & 0.96 & 0.73 & 1.26 & 0.77 & 32.80 & 4.47 & 0.22 & \\
\hline Follow-up years & & & & & & & & & & 0.64 \\
\hline$<10$ & 908,252 & 9 & 1.12 & 1.02 & 1.22 & 0.02 & 38.00 & 12.91 & 0.12 & \\
\hline$\geq 10$ & $2,979,333$ & 19 & 1.13 & 1.06 & 1.21 & $<0.001$ & 66.2 & 53.32 & $<0.001$ & \\
\hline Publication years & & & & & & & & & & 0.55 \\
\hline$\leq 2000$ & 95,532 & 9 & 1.1 & 0.9 & 1.4 & 0.5 & 64.50 & 22.51 & $<0.001$ & \\
\hline $2001-2009$ & $1,381,865$ & 5 & 1.3 & 1.0 & 1.6 & $<0.001$ & 81.50 & 21.60 & $<0.001$ & \\
\hline$\geq 2010$ & $2,410,188$ & 14 & 1.1 & 1.0 & 1.2 & $<0.001$ & 39.8 & 21.59 & 0.06 & \\
\hline Method of diabetes ascertainment & & & & & & & & & & 0.24 \\
\hline KDM & $2,486,016$ & 18 & 1.17 & 1.07 & 1.26 & $<0.001$ & 74.2 & 65.97 & $<0.001$ & \\
\hline NDM & 590,506 & 6 & 1.05 & 0.90 & 1.21 & 0.20 & 32.10 & 7.36 & 0.6 & \\
\hline $\mathrm{KDM}, \mathrm{NDM}$ & $1,363,765$ & 9 & 1.05 & 0.97 & 1.15 & 0.3 & 16.40 & 9.56 & $<0.001$ & \\
\hline Treated diabetes & NA & & & & & & & & & \\
\hline Cancer mortality & $4,482,501$ & 14 & & & & & & & & \\
\hline Age (years) & & & & & & & & & & 0.92 \\
\hline$<60$ & $3,361,850$ & 12 & 1.01 & 0.95 & 1.07 & 0.75 & 0.00 & 10.69 & 0.47 & \\
\hline$\geq 60$ & 66,820 & 1 & 1.02 & 0.88 & 1.18 & 0.81 & NA & 0.00 & NA & \\
\hline Others & 52,655 & 1 & 1.04 & 0.99 & 1.09 & 0.17 & NA & 0.72 & NA & \\
\hline Location & & & & & & & & & & 0.56 \\
\hline Asia & $2,795,136$ & 8 & 1.01 & 0.96 & 1.08 & 0.65 & 0.00 & 5.33 & 0.62 & \\
\hline Western Europe & 276,141 & 3 & 0.94 & 0.58 & 1.51 & 0.80 & 53.50 & 4.30 & 0.12 & \\
\hline North America & $1,411,224$ & 3 & 1.04 & 0.99 & 1.09 & 0.15 & 0.00 & 0.03 & 0.98 & \\
\hline Others & NA & & & & & & & & & \\
\hline Follow-up years & & & & & & & & & & 0.47 \\
\hline$<10$ & 881,061 & 3 & 1.08 & 0.94 & 1.23 & 0.29 & 0.00 & 1.45 & 0.49 & \\
\hline$\geq 10$ & $3,601,440$ & 11 & 1.02 & 0.98 & 1.06 & 0.32 & 0.00 & 9.18 & 0.52 & \\
\hline \multicolumn{11}{|l|}{ Publication years } \\
\hline$\leq 2000$ & 5131 & 1 & 1.11 & 0.31 & 3.94 & 0.87 & NA & 0.00 & NA & 0.73 \\
\hline 2001-2009 & $1,327,437$ & 2 & 1.05 & 0.91 & 1.20 & 0.50 & 5.10 & 1.05 & 0.31 & \\
\hline$\geq 2010$ & $3,149,933$ & 11 & 1.02 & 0.98 & 1.06 & 0.30 & 0.00 & 9.99 & 0.44 & \\
\hline Method of diabetes ascertainment & & & & & & & & & & 0.72 \\
\hline KDM & $2,094,903$ & 9 & 1.03 & 0.90 & 1.19 & 0.65 & 77.90 & 36.21 & $<0.001$ & \\
\hline NDM & 557,524 & 2 & 1.07 & 0.96 & 1.18 & 0.22 & 0.00 & 0.04 & 0.84 & \\
\hline KDM, NDM & $2,369,318$ & 4 & 1.03 & 0.99 & 1.08 & 0.16 & 0.00 & 1.16 & 0.764 & \\
\hline
\end{tabular}


Table 2 Sensitivity analyses of women-to-men ratio of relative risks for the outcomes associated with diabetes (Continued)

\begin{tabular}{|c|c|c|c|c|c|c|c|c|c|c|}
\hline & Individuals & $N$ & RRR & Lower & Upper & $P$ value & Test fo & heteros & neity & $P$ value for interaction \\
\hline & & & & & & & $P(\%)$ & $x^{2}$ & $P$ value & \\
\hline Treated diabetes & 18,280 & 1 & 0.99 & 0.56 & 1.74 & 0.96 & NA & 0 & NA & \\
\hline CVD mortality & $2,067,486$ & 23 & & & & & & & & \\
\hline Age (years) & & & & & & & & & & 0.91 \\
\hline$<60$ & 867,999 & 18 & 1.26 & 1.01 & 1.56 & 0.04 & 72.20 & 61.20 & $<0.001$ & \\
\hline$\geq 60$ & 106,601 & 3 & 1.12 & 0.98 & 1.29 & 0.10 & 5.70 & 2.12 & 0.35 & \\
\hline Others & $1,092,886$ & 2 & 1.53 & 0.77 & 3.04 & 0.23 & 96.60 & 29.05 & $<0.001$ & \\
\hline Location & & & & & & & & & & 0.64 \\
\hline Asia & 159,835 & 6 & 1.08 & 0.96 & 1.22 & 0.20 & 0.00 & 4.95 & 0.42 & \\
\hline Western Europe & 460,756 & 8 & 1.49 & 1.17 & 1.90 & $<0.001$ & 58.70 & 16.96 & 0.02 & \\
\hline North America & $1,415,878$ & 6 & 1.33 & 1.03 & 1.72 & 0.03 & 88.20 & 42.22 & $<0.001$ & \\
\hline Others & 31,017 & 3 & 1.12 & 0.75 & 1.67 & 0.57 & 0.00 & 0.53 & 0.77 & \\
\hline Follow-up years & & & & & & & & & & 0.38 \\
\hline$<10$ & 433,100 & 6 & 1.08 & 0.96 & 1.22 & 0.19 & 0.00 & 4.13 & 0.53 & \\
\hline$\geq 10$ & $1,634,386$ & 17 & 1.35 & 1.13 & 1.62 & $<0.001$ & 83.00 & 93.96 & $<0.001$ & \\
\hline Publication years & & & & & & & & & & 0.13 \\
\hline$\leq 2000$ & 54,288 & 4 & 1.36 & 0.75 & 2.47 & 0.31 & 79.10 & 14.33 & $<0.001$ & \\
\hline $2001-2009$ & 142,444 & 6 & 1.63 & 1.04 & 2.57 & 0.03 & 83.50 & 30.31 & $<0.001$ & \\
\hline$\geq 2010$ & $1,870,754$ & 13 & 1.09 & 1.06 & 1.12 & $<0.001$ & 0.00 & 4.62 & 0.97 & \\
\hline Method of diabetes ascertainment & & & & & & & & & & 0.53 \\
\hline KDM & $1,876,261$ & 11 & 1.20 & 1.02 & 1.42 & 0.03 & 85.10 & 66.94 & $<0.001$ & \\
\hline NDM & 42,944 & 3 & 1.40 & 0.84 & 2.35 & 0.20 & 74.50 & 7.85 & 0.02 & \\
\hline KDM, NDM & 152,371 & 11 & 1.31 & 0.95 & 1.82 & 0.10 & 73.10 & 37.23 & $<0.001$ & \\
\hline Treated diabetes & NA & & & & & & & & & \\
\hline CHD mortality & $2,050,929$ & 23 & & & & & & & & \\
\hline Age (years) & & & & & & & & & & 0.88 \\
\hline$<60$ & 864,790 & 15 & 1.52 & 1.22 & 1.90 & $<0.001$ & 39.20 & 23.02 & 0.06 & \\
\hline$\geq 60$ & 89,838 & 4 & 1.68 & 1.22 & 2.30 & $<0.001$ & 0.00 & 2.69 & 0.44 & \\
\hline Others & $1,096,301$ & 4 & 1.65 & 0.90 & 3.04 & 0.11 & 89.70 & 29.18 & $<0.001$ & \\
\hline Location & & & & & & & & & & 0.88 \\
\hline Asia & 692,384 & 5 & 1.53 & 0.99 & 2.38 & 0.06 & 61.10 & 10.29 & 0.04 & \\
\hline Western Europe & 242,624 & 8 & 1.86 & 1.42 & 2.45 & $<0.001$ & 41.60 & 11.98 & 0.10 & \\
\hline North America & $1,113,375$ & 9 & 1.17 & 1.13 & 1.22 & $<0.001$ & 0.00 & 7.26 & 0.51 & \\
\hline Others & 2546 & 1 & 3.11 & 0.79 & 12.23 & 0.11 & NA & 0.00 & NA & \\
\hline Follow-up years & & & & & & & & & & 0.17 \\
\hline$<10$ & 606,561 & 6 & 1.23 & 0.85 & 1.79 & 0.23 & 27.20 & 6.87 & 0.27 & \\
\hline$\geq 10$ & $1,371,125$ & 14 & 1.75 & 1.33 & 2.31 & 0.00 & 78.50 & 60.43 & $<0.001$ & \\
\hline Others & 73,243 & 3 & 1.38 & 0.95 & 2.02 & 0.10 & 0.00 & 0.86 & 0.65 & \\
\hline Publication years & & & & & & & & & & 0.20 \\
\hline$\leq 2000$ & 111,122 & 10 & 1.66 & 1.21 & 2.27 & 0.00 & 41.90 & 15.49 & 0.08 & \\
\hline $2001-2009$ & 118,915 & 6 & 1.84 & 1.25 & 2.71 & 0.00 & 32.80 & 7.44 & 0.19 & \\
\hline$\geq 2010$ & $1,820,892$ & 7 & 1.30 & 1.12 & 1.52 & 0.00 & 41.00 & 10.17 & 0.12 & \\
\hline Method of diabetes ascertainment & & & & & & & & & & 0.85 \\
\hline KDM & $1,457,769$ & 14 & 1.52 & 1.20 & 1.92 & 0.00 & 78.10 & 59.23 & $<0.001$ & \\
\hline
\end{tabular}


Table 2 Sensitivity analyses of women-to-men ratio of relative risks for the outcomes associated with diabetes (Continued)

\begin{tabular}{|c|c|c|c|c|c|c|c|c|c|c|}
\hline & Individuals & $N$ & RRR & Lower & Upper & $P$ value & Test for & heteros & neity & $P$ value for interaction \\
\hline & & & & & & & $P(\%)$ & $x^{2}$ & $P$ value & \\
\hline NDM & 119,825 & 4 & 1.90 & 0.98 & 3.70 & 0.06 & 70.70 & 10.26 & 0.02 & \\
\hline KDM, NDM & 543,435 & 7 & 1.34 & 1.14 & 1.57 & 0.00 & 0.00 & 5.42 & 0.49 & \\
\hline Treated diabetes & NA & & & & & & & & & \\
\hline Stroke mortality & $2,292,387$ & 15 & & & & & & & & \\
\hline Age (years) & & & & & & & & & & 0.71 \\
\hline$<60$ & $1,078,421$ & 10 & 1.12 & 0.98 & 1.28 & 0.11 & 0.00 & 7.36 & 0.60 & \\
\hline$\geq 60$ & 105,674 & 2 & 1.06 & 0.85 & 1.33 & 0.61 & 0.00 & 0.03 & 0.86 & \\
\hline Others & $1,108,292$ & 3 & 1.07 & 0.99 & 1.15 & 0.08 & 0.00 & 1.67 & 0.43 & \\
\hline Location & & & & & & & & & & 0.42 \\
\hline Asia & 764,335 & 7 & 1.11 & 0.97 & 1.26 & 0.12 & 0.00 & 5.04 & 0.54 & \\
\hline Western Europe & 132,562 & 5 & 1.36 & 0.97 & 1.90 & 0.07 & 0.00 & 1.60 & 0.81 & \\
\hline North America & $1,392,944$ & 2 & 1.06 & 0.98 & 1.13 & 0.13 & 0.00 & 0.08 & 0.78 & \\
\hline Others & 2546 & 1 & 0.46 & 0.03 & 7.76 & 0.59 & NA & 0.00 & NA & \\
\hline Follow-up years & & & & & & & & & & 0.58 \\
\hline$<10$ & 903,575 & 4 & 1.12 & 0.96 & 1.30 & 0.14 & 0.00 & 2.62 & 0.45 & \\
\hline$\geq 10$ & $1,388,812$ & 11 & 1.07 & 1.00 & 1.14 & 0.06 & 0.00 & 6.48 & 0.77 & \\
\hline Others & NA & & & & & & & & & \\
\hline Publication years & & & & & & & & & & 0.25 \\
\hline$\leq 2000$ & 67,444 & 5 & 1.39 & 0.90 & 2.14 & 0.14 & 0.00 & 2.67 & 0.62 & \\
\hline 2001-2009 & 101,874 & 3 & 1.09 & 0.63 & 1.91 & 0.75 & 23.90 & 2.63 & 0.27 & \\
\hline$\geq 2010$ & $2,123,069$ & 7 & 1.07 & 1.00 & 1.14 & 0.04 & 0.00 & 2.66 & 0.85 & \\
\hline Method of diabetes ascertainment & & & & & & & & & & 0.27 \\
\hline KDM & $1,720,989$ & 10 & 1.06 & 1.00 & 1.13 & 0.07 & 0.00 & 8.36 & 0.50 & \\
\hline NDM & 61,368 & 2 & 1.37 & 0.70 & 2.66 & 0.36 & 24.80 & 1.33 & 0.25 & \\
\hline KDM, NDM & 532,544 & 4 & 1.18 & 0.98 & 1.42 & 0.09 & 0.40 & 3.01 & 0.39 & \\
\hline Treated diabetes & NA & & & & & & & & & \\
\hline
\end{tabular}

Abbreviations: $N$ number of studies, NA not available, CVD cardiovascular disease, CHD coronary heart disease

Biases embedded within health service need to be considered. There is evidence that women, compared to their male counterparts, are less likely to have their risk factors assessed by physicians when they present in primary care. Compared to older women at high risk of CVD, younger women at high risk were less likely to receive preventative treatment [82]. Indeed, women with diabetes or CVD are diagnosed later and have a lower frequency of statin therapy, aspirin use, and ACE inhibitor and $\beta$-blocker use than men [83]. Some studies observed lower medication adherence in women than in men $[84,85]$. Where medication is adhered to, women do not always benefit to the same extent as men given the well-documented issues with under-representation of women in clinical trials [66]. What is more, younger women's symptoms often present differently to those of men of the same age. There may be less myocardial ischemic preconditioning in women, and subsequently greater susceptibility to ischemia. Therefore, sex and gender disparities in treatment may exacerbate the sex differences in CVD owing to diabetes [86, 87].

Some studies show that the proportion of undiagnosed diabetes to total diabetes in men is higher than that in women [88, 89]. In studies that used self-reported measures to identify diabetes, there was a greater proportion of undiagnosed diabetes in men. It is possible that this concealed the true excess risk of mortality conferred by diabetes in men and subsequent sex-specific relative risk estimates that were calculated for women and men.

Our finding that diabetes elevates the risk of all-cancer mortality is in general agreement with previous reviews [90]. However, most have looked at site-specific cancers; sexspecific associations from which results have been inconsistent. One meta-analysis indicated that diabetes conferred a stronger positive relationship with kidney cancer mortality and gastric cancer risk in women than in men [91, 92]. 
Others have found that diabetes increased the risk of esophageal cancer and leukemia in men, but not in women [93, 94]. Prospective studies showed that HRs for noncancer, non-vascular deaths among participants with diabetes, as compared to those without diabetes, were also significantly higher among women (women: HR $2.20,95 \% \mathrm{CI}$ 1.91 to 2.52 ; men: HR $1.58,95 \%$ CI 1.41 to $1.76 ; P_{\text {interaction }}<$ 0.001 ). The absence of sex disparities for infectious disease and respiratory disease mortality did not contribute to the sex difference for non-cancer, non-vascular deaths [95]. Therefore, future research is needed to distinguish whether and to what extent the excess risk of cause-specific mortality from non-cancer, non-vascular deaths conferred by diabetes differs between the sexes, such as kidney disease mortality.

\section{Strengths and limitations}

The present meta-analysis has several main strengths. Firstly, the large number of participants ensured greater statistical power to detect sex differences than some previous individual studies. Secondly, using within-study comparisons to estimate sex-specific relationships between diabetes and cause-specific outcomes can minimize the role of extraneous, between-study factors. Thirdly, the study comprehensively evaluated the sex-specific associations for a range of important health outcomes: all-cause, all-cancer, CVD, and other cause-specific mortality. This has the potential to be more informative in aiding our understanding of the sex-specific burden of disease from diabetes. Fourthly, the detailed subgroup, sensitivity, and influence analyses ensure the robustness of the study findings.

There are also some specific limitations of this review that merit consideration. Firstly, there was some heterogeneity across studies for outcomes such as all-cause, CVD, and CHD mortality, but subgroup analyses and meta-regression analyses on study characteristics including age, geographical location, duration of follow-up, publish year, and method of diabetes ascertainment did not provide any evidence of a substantial effect of these differences on the results. Secondly, the present metaanalysis is based on prospective cohort studies, and the observational design is open to biases due to the residual confounding from incompletely measured factors and cannot elucidate causal relationship. Thirdly, the present meta-analysis did not include non-fatal events, which limited the ability to assess the presence of sex differences in risk for the incidence. Fourthly, differences in definition of diabetes, diabetes duration, duration of follow-up, and populations might have contributed to the sex differences in the association of diabetes with risk of death and CVD; although subgroup, metaregression, and sensitivity analyses were conducted to explore the potential between-study heterogeneity, lack of individual participant data limited more in-depth sensitivity analyses than were reported here. Fifthly, our analysis cannot ascertain the underlying cause of the sex differences in the relationship between diabetes and the risk of CVD mortality. Finally, the potential publication bias was also a concern. Although we did not observe any apparent publication bias in our statistical tests, it was still difficult to completely rule this out.

\section{Conclusions}

Our study demonstrated that women with diabetes have a greater risk of all-cause mortality, particularly from CHD, compared with men with the same condition. An increased understanding and appreciation of sex differences in the relationship between diabetes and risk of all-cause and CHD mortality is required given the substantial global and regional burden of NCDs. Women with diabetes should be treated and managed throughout their life course with the view to reduce the burden of other diseases related to diabetes. In the future, indepth sex-specific analyses from randomized trials and other studies using approaches like Mendelian randomization are needed to clarify the biological, behavioral, or social mechanisms involved.

\section{Additional file}

Additional file 1: The additional file 1 contains additional information and analysis. Search strategies in PubMed and EMBASE. Table S1. Study protocol: PRISMA 2009 Checklist. Table S2. Quality of included studies assessed with Newcastle-Ottawa Scale. Figure S1. Pooled RRs for the risk of cancer mortality. Figure S2. Pooled women-to-men RRRs for the risk of cancer mortality. Figure S3. Pooled RRs for the risk of CVD mortality. Figure S4. Pooled womento-men RRRs for the risk of CVD mortality. Figure S5. Pooled RRs for the risk of CHD mortality. Figure S6. Pooled women-to-men RRRs for the risk of CHD mortality. Figure S7. Pooled women-to-men RRRs for the risk of stroke mortality. Figure S8. Pooled RRs for the risk of respiratory mortality. Figure S9. Pooled RRs for the risk of infectious mortality. (DOCX 1577 kb)

\section{Abbreviations}

BMI: Body mass index; CHD: Coronary heart disease; Cl: Confidence intervals; CVD: Cardiovascular disease; GBD: Global Burden of Disease Study; HR: Hazard ratio; KDM: Known diabetes; N: Number of studies; NA: Not available; NCDs: Non-communicable diseases; NDM: Newly diagnosed diabetes; NOS: Newcastle-Ottawa quality assessment scale; OR: Odds ratio; RR: Relative risk; RRR: Ratio of RR

\section{Acknowledgements}

Manuscript feedback from the editor and reviewers was much appreciated. The authors thank the National Center for Health Statistics of the Centers for Disease Control and Prevention for sharing the NHIS data.

\section{Authors' contributions}

$Y W, A O$, and $C Y$ were responsible for the conception and design of the study. YW, YJ, and LW were responsible for the acquisition of data and analysis. $Y J$ and $Y W$ were responsible for the statistical analysis. YW, AO, YJ, $J H, Y L, Y Z$, and $C Y$ wrote and revised the manuscript. All authors read and approved the final manuscript.

\section{Funding}

CY and YW receive funding from the National Natural Science Foundation of China (Grant No.81773552) and the National Key Research and Development 
Program of China (No. 2018YFC1315302, 2017YFC 1200502); AO receives funding from the Heart Foundation Australia.

\section{Availability of data and materials}

All data and materials analyzed in this manuscript are authentic and derived from published studies except data from NHIS. For NHIS, the data we used are publicly available. The datasets used and/or analyzed during the current study are available from the corresponding author on reasonable request.

\section{Ethics approval and consent to participate}

This systematic review and meta-analysis includes previously published observational studies and public-use data from NHIS. In addition, the NHIS was approved by the National Center for Health Statistics ethics review board. We could not influence the design of the prior studies upon which this work is based and cannot comment on individual ethics approval or consent. Patients were not involved in the conduct of our epidemiological study, and there is no identifiable data.

\section{Consent for publication}

Not applicable.

\section{Competing interests}

The authors declare that they have no competing interests.

\section{Author details}

${ }^{1}$ Department of Epidemiology and Biostatistics, School of Health Sciences, Wuhan University, 185 Donghu Road, Wuchang District, Wuhan 430071, China. ${ }^{2}$ Melbourne School of Population and Global Health, University of Melbourne, Carlton, Australia. ${ }^{3}$ Department of Endocrinology, Second Clinical Medical College, Shanxi Medical University, 382 Wuyi Road, Taiyuan 030001, China. ${ }^{4}$ Department of Neurology, Renji Hospital, School of Medicine, Shanghai Jiaotong University, Shanghai, China. ${ }^{5}$ School of Nursing, Guangdong Pharmaceutical University, 283 Jianghai Avenue, Haizhu District, Guangzhou, China. ${ }^{6}$ Global Health Institute, Wuhan University, Wuhan, China.

\section{Received: 26 December 2018 Accepted: 29 May 2019}

\section{Published online: 12 July 2019}

\section{References}

1. GBD 2016 Risk Factors Collaborators. Global, regional, and national comparative risk assessment of 84 behavioral, environmental and occupational, and metabolic risks or clusters of risks, 1990-2016: a systematic analysis for the Global Burden of Disease Study 2016. Lancet. 2017;390:1345-422.

2. World Health Organization. Global action plan for the prevention and control of noncommunicable diseases 2013-2020. Available from http:// www.who.int/nmh/events/ncd_action_plan/en/. Accessed 9 Dec 2018

3. Wild S, Roglic G, Green A, et al. Global prevalence of diabetes: estimates for the year 2000 and projections for 2030. Diabetes Care. 2004;27:1047-53.

4. International Diabetes Federation. IDF Diabetes atlas. Brussels: International Diabetes Federation; 2017. http://www.diabetesatlas.org/resources/2017atlas.html. Accessed 1 Dec 2018

5. Whiting DR, Guariguata L, Weil C, et al. IDF diabetes atlas: global estimates of the prevalence of diabetes for 2011 and 2030. Diabetes Res Clin Pract. 2011;94:311-21.

6. Campbell PT, Newton CC, Patel AV, et al. Diabetes and cause-specific mortality in a prospective cohort of one million U.S. adults. Diabetes Care. 2012;35:1835-44.

7. Peters SA, Huxley RR, Woodward M. Diabetes as a risk factor for stroke in women compared with men: a systematic review and meta-analysis of 64 cohorts, including 775,385 individuals and 12,539 strokes. Lancet. 2014;383: 1973-80.

8. Peters SA, Huxley RR, Woodward M. Diabetes as risk factor for incident coronary heart disease in women compared with men: a systematic review and meta-analysis of 64 cohorts including 858,507 individuals and 28,203 coronary events. Diabetologia. 2014:57:1542-51.

9. Fang H, Shan $S$, Zhou Y, et al. Diabetes mellitus and the risk of gastrointestinal cancer in women compared with men: a meta-analysis of cohort studies. BMC Cancer. 2018;18:422.
10. Stroup DF, Berlin JA, Morton SC, et al. Meta-analysis of observational studies in epidemiology: a proposal for reporting. Meta-analysis Of Observational Studies in Epidemiology (MOOSE) group. JAMA. 2000;283:2008-12.

11. Moher D, Liberati A, Tetzlaff J, et al. Preferred reporting items for systematic reviews and meta-analyses: the PRISMA statement. BMJ. 2009;339:b2535.

12. GA Wells, B Shea, D O'Connell, et al. The Newcastle-Ottawa Scale (NOS) for assessing the quality of nonrandomized studies in meta-analyses. Available from http://www.ohri.ca/programs/clinical_epidemiology/oxford.asp. Accessed 9 Dec 2018

13. Zhang J, Yu KF. What's the relative risk? A method of correcting the odds ratio in cohort studies of common outcomes. JAMA. 1998;280:1690-1.

14. Huxley RR, Woodward M. Cigarette smoking as a risk factor for coronary heart disease in women compared with men: a systematic review and meta-analysis of prospective cohort studies. Lancet. 2011;378:1297-305.

15. Higgins JP, Thompson SG. Quantifying heterogeneity in a meta-analysis. Stat Med. 2002;21:1539-58.

16. Sterne JA, Egger M. Funnel plots for detecting bias in meta-analysis: guidelines on choice of axis. J Clin Epidemiol. 2001;54:1046-55.

17. Jousilahti $\mathrm{P}$, Vartiainen $\mathrm{E}$, Tuomilehto J, et al. Sex, age, cardiovascular risk factors, and coronary heart disease: a prospective follow-up study of 14786 middle-aged men and women in Finland. Circulation. 1999;99:1165-72.

18. Oba S, Nagata C, Nakamura K, et al. Self-reported diabetes mellitus and risk of mortality from all causes, cardiovascular disease, and cancer in Takayama: a population-based prospective cohort study in Japan. J Epidemiol. 2008;18: 197-203.

19. Hu G, Jousilahti P, Qiao Q, et al. Sex differences in cardiovascular and total mortality among diabetic and non-diabetic individuals with or without history of myocardial infarction. Diabetologia. 2005;48:856-61.

20. Madssen $\mathrm{E}$, Vatten $\mathrm{L}$, Nilsen $\mathrm{Tl}$, et al. Abnormal glucose regulation and gender-specific risk of fatal coronary artery disease in the HUNT 1 study. Scand Cardiovasc J. 2012;46:219-25.

21. DECODE Study Group, the European Diabetes Epidemiology Group. Glucose tolerance and cardiovascular mortality: comparison of fasting and 2-hour diagnostic criteria. Arch Intern Med. 2001;161:397-405.

22. Keil JE, Sutherland SE, Knapp RG, et al. Mortality rates and risk factors for coronary disease in black as compared with white men and women. N Engl J Med. 1993;329:73-8.

23. Friberg J, Scharling $\mathrm{H}$, Gadsbøll N, et al. Comparison of the impact of atrial fibrillation on the risk of stroke and cardiovascular death in women versus men (The Copenhagen City Heart Study). Am J Cardiol. 2004;94:889-94.

24. Collins VR, Dowse GK, Ram P, et al. Non-insulin-dependent diabetes and 11year mortality in Asian Indian and Melanesian Fijians. Diabet Med. 1996;13: 125-32.

25. Bozorgmanesh M, Hadaegh F, Sheikholeslami F, et al. Cardiovascular risk and all-cause mortality attributable to diabetes: Tehran lipid and glucose study. J Endocrinol Invest. 2012;35:14-20.

26. Kleinman JC, Donahue RP, Harris Ml, et al. Mortality among diabetics in a national sample. Am J Epidemiol. 1988;128:389-401.

27. Magliano DJ, Söderberg S, Zimmet PZ, et al. Mortality, all-cause and cardiovascular disease, over 15 years in multiethnic mauritius: impact of diabetes and intermediate forms of glucose tolerance. Diabetes Care. 2010; 33:1983-9.

28. Barrett-Connor EL, Cohn BA, Wingard DL, et al. Why is diabetes mellitus a stronger risk factor for fatal ischemic heart disease in women than in men? The Rancho Bernardo Study. JAMA. 1991;265:627-31.

29. Fraser GE, Strahan TM, Sabaté J, et al. Effects of traditional coronary risk factors on rates of incident coronary events in a low-risk population. The Adventist Health Study. Circulation. 1992;86:406-13.

30. Sievers ML, Nelson RG, Knowler WC, et al. Impact of NIDDM on mortality and causes of death in Pima Indians. Diabetes Care. 1992;15:1541-9.

31. Seeman T, Mendes de Leon C, Berkman L, et al. Risk factors for coronary heart disease among older men and women: a prospective study of community-dwelling elderly. Am J Epidemiol. 1993;138:1037-49.

32. Wang WS, Wahlqvist ML, Hsu CC, et al. Age- and gender-specific population attributable risks of metabolic disorders on all-cause and cardiovascular mortality in Taiwan. BMC Public Health. 2012;12:111.

33. Natarajan $\mathrm{S}$, Liao Y, Cao G, et al. Sex differences in risk for coronary heart disease mortality associated with diabetes and established coronary heart disease. Arch Intern Med. 2003;163:1735-40.

34. Vilbergsson S, Sigurdsson G, Sigvaldason $\mathrm{H}$, et al. Coronary heart disease mortality amongst non-insulin-dependent diabetic subjects in Iceland: the 
independent effect of diabetes. The Reykjavik Study 17-year follow up. J Intern Med. 1998:244:309-16.

35. Qvist J, Johansson SE, Johansson LM, et al. Multivariate analyses of mortality from coronary heart disease due to biological and behavioural factors. Scand J Soc Med. 1996;24:67-76.

36. Tunstall-Pedoe H, Woodward M, Tavendale R, et al. Comparison of the prediction by 27 different factors of coronary heart disease and death in men and women of the Scottish Heart Health Study: cohort study. BMJ. 1997:315:722-9

37. Nilsson PM, Johansson SE, Sundquist J, et al. Low educational status is a risk factor for mortality among diabetic people. Diabet Med. 1998;15:213-9.

38. Imazu M, Sumii K, Yamamoto $H$, et al. Influence of type 2 diabetes mellitus on cardiovascular disease mortality: findings from the Hawaii-Los AngelesHiroshima study. Diabetes Res Clin Pract. 2002;57:61-9.

39. Hart CL, Hole DJ, Smith GD, et al. Risk factors and 20-year stroke mortality in men and women in the Renfrew/Paisley study in Scotland. Stroke. 1999;30: 1999-2007.

40. Bragg F, Holmes MV, lona A, et al. Association Between Diabetes and Cause-Specific Mortality in Rural and Urban Areas of China. JAMA. 2017;317: 280-9.

41. Kato M, Noda M, Mizoue $T$, et al. Diagnosed diabetes and premature death among middle-aged Japanese: results from a large-scale population-based cohort study in Japan (JPHC study). BMJ Open. 2015;5:e007736.

42. Johansen $\mathrm{H}$, Semenciw $\mathrm{R}$, Morrison $\mathrm{H}$, et al. Important risk factors for death in adults: a 10-year follow-up of the Nutrition Canada survey cohort. CMAJ. 1987:136:823-8

43. Suemoto CK, Lebrao ML, Duarte YA, et al. Effects of body mass index, abdominal obesity, and type 2 diabetes on mortality in communitydwelling elderly in Sao Paulo, Brazil: analysis of prospective data from the SABE study. J Gerontol A Biol Sci Med Sci. 2015;70:503-10.

44. Jee $\mathrm{SH}$, Ohrr H, Sull JW, et al. Fasting serum glucose level and cancer risk in Korean men and women. JAMA. 2005;293:194-202.

45. Fraser GE, Shavlik DJ, et al. Risk factors for all-cause and coronary heart disease mortality in the oldest-old. The Adventist Health Study. Arch Intern Med. 1997;157:2249-58.

46. Moe B, Eilertsen E, Nilsen TI, et al. The combined effect of leisure-time physical activity and diabetes on cardiovascular mortality: the Nord-Trondelag Health (HUNT) cohort study, Norway. Diabetes Care. 2013;36:690-5.

47. Liu L. Social connections, diabetes mellitus, and risk of mortality among white and African-American adults aged 70 and older: an eight-year followup study. Ann Epidemiol. 2011;21:26-33.

48. Vimalananda VG, Biggs ML, Rosenzweig $\mathrm{J}$, et al. The influence of sex on cardiovascular outcomes associated with diabetes among older black and white adults. J Diabetes Complications. 2014:28:316-22.

49. Eichner JE, Wang W, Zhang Y, et al. Tobacco use and cardiovascular disease among American Indians: the strong heart study. Int J Environ Res Public Health. 2010;7:3816-30.

50. Bozorgmanesh M, Hadaegh F, Sheikholeslami F, et al. Shadow of diabetes over cardiovascular disease: comparative uantification of population-attributable allcause and cardiovascular mortality. Cardiovasc Diabetol. 2012;11:69.

51. Moe B, Augestad LB, Nilsen TI, et al. Diabetes severity and the role of leisure time physical exercise on cardiovascular mortality: the Nord-Trøndelag Health study (HUNT), Norway. Cardiovasc Diabetol. 2013;12:83.

52. Kakehi E, Kotani K, Ishikawa S, et al. Relationship between screening plasma glucose concentrations and cancer- and all-cause mortality: the Jich Medical School(JMS) cohort study. J Public Health. 2014;22:505-11.

53. Shen C, Schooling CM, Chan WM, et al. Self-reported diabetes and mortality in a prospective Chinese elderly cohort study in Hong Kong. Prev Med. 2014:64:20-6.

54. Hiltunen L. Ten-year mortality and glucose tolerance status in an elderly Finnish population. Diabetes Res Clin Pract. 2005:69:81-7.

55. Gordon-Dseagu VL, Shelton N, Mindell J, et al. Diabetes mellitus and mortality from all-causes, cancer, cardiovascular and respiratory disease: evidence from the Health Survey for England and Scottish Health Survey cohorts. J Diabetes Complications. 2014;28:791-7.

56. Yeh $\mathrm{HC}$, Platz EA, Wang NY, et al. A prospective study of the associations between treated diabetes and cancer outcomes. Diabetes Care. 2012;35: $113-8$

57. Chen Y, Wu F, Saito E, et al. Association between type 2 diabetes and risk of cancer mortality: a pooled analysis of over 771,000 individuals in the Asia Cohort Consortium. Diabetologia. 2017;60:1022-32.
58. Zhou XH, Qiao Q, Zethelius B, et al. Diabetes, prediabetes and cancer mortality. Diabetologia. 2010;53:1867-76.

59. Drake I, Gullberg B, Sonestedt E, et al. Type 2 diabetes, adiposity and cancer morbidity and mortality risk taking into account competing risk of noncancer deaths in a prospective cohort setting. Int J Cancer. 2017;141:1170-80.

60. Preis SR, Hwang SJ, Coady S, et al. Trends in all-cause and cardiovascular disease mortality among women and men with and without diabetes mellitus in the Framingham Heart Study, 1950 to 2005. Circulation. 2009;119:1728-35.

61. Natarajan S, Liao Y, Sinha D, et al. Sex differences in the effect of diabetes duration on coronary heart disease mortality. Arch Intern Med. 2005;165:430-5.

62. Hirakawa Y, Ninomiya T, Kiyohara Y, et al. Age-specific impact of diabetes mellitus on the risk of cardiovascular mortality: An overview from the evidence for Cardiovascular Prevention from Observational Cohorts in the Japan Research Group (EPOCH-JAPAN). J Epidemiol. 2017;27:123-9.

63. Alegre-Díaz J, Herrington W, López-Cervantes M, et al. Diabetes and CauseSpecific Mortality in Mexico City. N Engl J Med. 2016;375:1961-71.

64. Kannel WB, McGee DL. Diabetes and cardiovascular disease. The Framingham study. JAMA. 1979;241:2035-8.

65. Harris Ml, Director. Diabetes in america, 2nd edition. Diabetes Res Clin Pr 1995;30:75

66. Regensteiner JG, Golden S, Huebschmann AG, et al. Sex differences in the cardiovascular consequences of diabetes mellitus: a scientific statement from the american heart association. Circulation. 2015;132:2424.

67. Ostan R, Monti D, Gueresi $P$, et al. Gender, aging and longevity in humans: an update of an intriguing/neglected scenario paving the way to a genderspecific medicine. Clin Sci (Lond). 2016;130:1711-25.

68. Gouni-Berthold I, Berthold HK, Mantzoros CS, et al. Sex disparities in the treatment and control of cardiovascular risk factors in type 2 diabetes. Diabetes Care. 2008;31:1389-91.

69. Barrettconnor E. Sex differences in coronary heart disease why are women so superior? The 1995 Ancel Keys Lecture. Circulation. 1997;95:252-64.

70. Zeller T, Schnabel RB, Appelbaum S, et al. Low testosterone levels are predictive for incident atrial fibrillation and ischaemic stroke in men, but protective in women - results from the finrisk study. Eur J Prev Cardiol. 2018;25:1133-9.

71. Robert A, Kloner MD, Culley Carson III, et al. Testosterone and Cardiovascular Disease. JACC. 2016;67:545-57.

72. BarrettConnor $\mathrm{E}$. The rancho bernardo study: 40 years studying why women have less heart disease than men and how diabetes modifies women's usual cardiac protection. Glob Heart. 2013;8:95-104.

73. Basaria S, Coviello AD, Travison TG, et al. Adverse events associated with testosterone administration. N Engl J Med. 2010;363:109-22.

74. Celismorales CA, Welsh P, Lyall DM, et al. Associations of grip strength with cardiovascular, respiratory, and cancer outcomes and all cause mortality: prospective cohort study of half a million uk biobank participants. BMJ. 2018:361:k1651.

75. Ogden $\mathrm{CL}$, Carroll MD, Kit BK, et al. Prevalence of childhood and adult obesity in the united states, 2011-2012. JAMA. 2014;311:806.

76. Go AS, Mozaffarian D, Roger VL, et al. Executive summary: heart disease and stroke statistics--2013 update: a report from the American Heart Association. Circulation. 2013;127:143-52.

77. Franzini L, Ardigo D, Cavalot F, et al. Women show worse control of type 2 diabetes and cardiovascular disease risk factors than men: results from the MIND.IT Study Group of the Italian Society of Diabetology. Nutr Metab Cardiovasc Dis. 2013;23:235-41.

78. Gnatiuc L, Herrington WG, Halsey J, et al. Sex-specific relevance of diabetes to occlusive vascular and other mortality: a collaborative meta-analysis of individual data from 980793 adults from 68 prospective studies. Lancet Diabetes Endocrinol. 2018;6:538-46.

79. Huang $Y$, Cai $X$, Mai W, et al. Association between prediabetes and risk of cardiovascular disease and all-cause mortality: systematic review and metaanalysis. BMJ. 2016;355:15953.

80. Donahue RP, Rejman K, Rafalson LB, et al. Sex differences in endothelial function markers before conversion to pre-diabetes: does the clock start ticking earlier among women? The Western New York Study. Diabetes Care. 2007;30:354-9.

81. Haffner SM, Miettinen H, Stern MP. Relatively more atherogenic coronary heart disease risk factors, in prediabetic women than in prediabetic men. Diabetologia. 1997:40:711-7.

82. Hyun KK, Redfern J, Patel A, et al. Gender inequalities in cardiovascular risk factor assessment and management in primary healthcare. Heart. 2017;103: 492-8. 
83. Winston GJ, Barr RG, Carrasquillo O, et al. Sex and racial/ethnic differences in cardiovascular disease risk factor treatment and control among individuals with diabetes in the Multi-Ethnic Study of Atherosclerosis (MESA). Diabetes Care. 2009;32:1467-9.

84. Krämer HU, Elke R, Gernot R, et al. Gender disparities in diabetes and coronary heart disease medication among patients with type 2 diabetes: results from the Diana study. Cardiovasc Diabetol. 2012;11:88.

85. Manteuffel M, Williams S, Chen W, et al. Influence of patient sex and gender on medication use, adherence, and prescribing alignment with guidelines. J Womens Health(Larchmt). 2014;21:112-9.

86. Cenko E, Yoon J, Kedev S, et al. Sex differences in outcomes after stemi: effect modification by treatment strategy and age. JAMA Intern Med. 2018; 178:632-9.

87. Bugiardini R, Ricci B, Cenko E, et al. Delayed care and mortality among women and men with myocardial infarction. J Am Heart Assoc. 2017;6: e005968.

88. Dwyer-Lindgren L, Mackenbach JP, van Lenthe FJ, et al. Diagnosed and Undiagnosed Diabetes Prevalence by County in the U.S., 1999-2012. Diabetes Care. 2016;39:1556-62.

89. Muntoni S, Atzori L, Mereu R, et al. Prevalence of diagnosed and undiagnosed diabetes mellitus and impaired fasting glucose in Sardinia. Acta Diabetol. 2009:46:227-31.

90. Tsilidis KK, Kasimis JC, Lopez DS, et al. Type 2 diabetes and cancer: umbrella review of meta-analyses of observational studies. BMJ. 2015;350:g7607.

91. Ge Z, Ben Q, Qian J, et al. Diabetes mellitus and risk of gastric cancer: a systematic review and meta-analysis of observational studies. Eur J Gastroenterol Hepatol. 2011;23:1127-35.

92. Larsson SC. Diabetes mellitus and incidence of kidney cancer: a metaanalysis of cohort studies. Diabetologia. 2011;54:1013-8.

93. Huang $W$, Ren $H$, Ben Q, et al. Risk of esophageal cancer in diabetes mellitus: a meta-analysis of observational studies. Cancer Causes Control. 2012;23:263-72.

94. Castillo JJ, Mull N, Reagan JL, et al. Increased incidence of non-hodgkin lymphoma, leukemia, and myeloma in patients with diabetes mellitus type 2: a meta-analysis of observational studies. Blood. 2012;119:4845-50.

95. Seshasai SRK, Kaptoge S, Thompson A, et al. Diabetes mellitus, fasting glucose, and risk of cause-specific death. N Engl J Med. 2011;364:829.

\section{Publisher's Note}

Springer Nature remains neutral with regard to jurisdictional claims in published maps and institutional affiliations.

Ready to submit your research? Choose BMC and benefit from:

- fast, convenient online submission

- thorough peer review by experienced researchers in your field

- rapid publication on acceptance

- support for research data, including large and complex data types

- gold Open Access which fosters wider collaboration and increased citations

- maximum visibility for your research: over $100 \mathrm{M}$ website views per year

At BMC, research is always in progress.

Learn more biomedcentral.com/submissions 